\title{
Micellar Extraction of Active Ingredients of Plant Raw Materials as a Tool for Improving the Quality of Diet Supplements and Additional Substances ${ }^{+}$
}

\author{
Magdalena Malysa-Pasko*, Marcin Lukasiewicz, Gabriela Ziec, Ewa Slusarz \\ and Piotr Jakubowski \\ Faculty of Food Technology, University of Agriculture in Krakow, ul. Balicka 122, 30-149 Krakow, Poland; \\ rrlukasi@kinga.cyf-kr.edu.pl (M.L.); gabriela.ziec@gmail.com (G.Z.); e.slusarz@wp.pl (E.S.); \\ piotrek2612@poczta.onet.pl (P.J.) \\ * Correspondence: magdalena.malysa-pasko@urk.edu.pl or malysamagdalena@gmail.com \\ + Presented at the 22nd International Electronic Conference on Synthetic Organic Chemistry, 15 November- \\ 15 December 2018; Available online: https://sciforum.net/conference/ecsoc-22.
}

Published: 14 November 2018

\begin{abstract}
The micellar extraction method (micellar mediated extraction (MME)) is an alternative method of classical extraction, which takes place with the participation of surfactants. In this method, instead of an organic solvent, a highly efficient solution of surfactants is used, which dissolves the desired component in hydrophobic micelles. Moreover, micellar extraction is often used for separating analytes from complex matrices, enriching analytes in environmental research, as well as for determining trace amounts of heavy metals or toxins in biological samples. The main goal of the presented study was to compare conventional extraction (using ethanol solutions) with micellar extraction (carried out with whey protein isolated (WPI) solutions and whey protein concentrated (WPC). The test material consisted of dried elderberry (Sambucus nigra) fruits. The comparison of the obtained extracts was performed by analyzing the contents of reducing compounds, flavonoid content, and the ability to reduce iron (III) ions in a system of three variables: Temperature, concentration and time. The obtained results clearly show that the factor influencing the efficiency of micellar extraction using WPC and WPI was time. The higher ability to reduce iron (III) ions was characterized by WPC protein extract as opposed to WPI extracts. The content of flavonoids in micellar extraction using protein extracts from WPC was higher than with the use of protein extracts from WPI.
\end{abstract}

Keywords: micellar mediated extraction; elderberry; micelle; polyphenols

\section{Introduction}

The micellar extraction method (micellar mediated extraction, MME) is an alternative method of classical extraction, which takes place with the participation of surfactants. In this method, instead of an organic solvent, a highly-efficient solution of surface-active substances is used in hydrophobic micelles, which dissolves the desired component [1]. Moreover, micellar extraction is often used for separating analytes from complex matrices, enriching analytes in environmental research, as well as for determining trace amounts of heavy metals or toxins in biological samples [2]. In comparison with liquid-liquid or solid-liquid extraction methods, it does not require the use of toxic organic solvents, and the parameters that distinguish it from others are the simplicity of its implementation and the speed of the process [3]. In addition, it can be used for the extraction of biologically-active substances, such as vitamins $A, E, K$, and $B_{1}$, and salicylic acid from plant material. The efficiency of this method means that the extracted substances can be safely used in food, pharmaceuticals or cosmetics [2]. Due 
to low values of critical micellar concentration (CMC), neutral surfactants (nonionic and anionic/cationic systems) used in very small quantities is another advantage of this method. Nonionic surfactants have the best solubilizing properties. Factors that influence the dissolution capacity of a solution of surfactants include structure, type of surfactant, $\mathrm{pH}$ of the test sample, the presence of electrolytes, the presence of other organic materials (polymers and monomers), and temperature and time of the process $[4,5]$. The use of an appropriate surfactant for micellar extraction depends on the type of substance being tested. The structure of the surfactant used should enable its connection with the analyte to be determined. For this purpose, anionic, cationic, nonionic, and amphoteric surfactants are used. The concentration of a given surfactant is equally important because, in the case of exceeding the critical concentration of micellization (CMC) and reaching the cloud point, micelles are formed, which combine with the analyte, as is the case with nonionic compounds.

The formation of micellar systems is typical for surface-active substances (surfactants), of which molecules are composed of parts that differ in polarity. In diluted solutions, surfactants exist in the form of monomers, i.e., single molecules. As the colloidal solution develops, the concentration increases above a certain threshold, called the critical micellar concentration. Surfactant monomers accumulate spontaneously and form colloidal sizes, called micelles. The mechanism of micelle formation is associated with hydrophobic interactions [6]. The micelle structure consists of three surfaces: The surface area, the micelle core, and the volume phase area. The micelle core consists of nonpolar hydrocarbon chains, of which the first four methyl groups form the outer core and the remaining inner core. The surface area is built from polar groups of nonionic surfactants. Micelles are usually composed of 50-200 monomeric molecules, and their sizes and shapes are energy dependent and geometrical [7]. The size characteristic of a particular surfactant is the average number of aggregations corresponding to the average number of micelle surfactant molecules. Depending on the particular surfactant and the solution conditions, micelles can take various shapes, such as spherical or ellipsoidal beads [8]. Such a structure allows micellar aggregates to improve the solubility of hydrophobic materials and modify environmental features, such as viscosity and polarity [9].

Therefore, in order to give the highest process efficiency and carry out the extraction separation as easily as possible, a concentration of surfactants which is not lower than its CMC values is required. Another important factor is the $\mathrm{pH}$ of the test sample, which regulates the transfer of analytes to the micellar phase when the appropriate concentration of hydrogen ions is applied. The highest extraction efficiency is achieved at the $\mathrm{pH}$ value at which the uncharged form of the analyte is predominant [10].

Only $\mathrm{pH}$ does not affect the efficiency of the process [11]. A particularly important factor affecting the critical micellar concentration (CMC) in the micelle extraction is the proportion of neutral salt (e.g., $\mathrm{CaCl}_{2}, \mathrm{Na}_{2} \mathrm{SO}_{4}, \mathrm{NaCl}$ ). During the addition of salt, the sizes of the micelles formed increase, as do the number of aggregates. This affects the better extraction efficiency of polar substances as opposed to hydrophobic compounds. This factor is applicable to the extraction of analytes from complex matrices (environmental samples) [12]. An important role during the extraction process is heating the sample at a given temperature, during which the separation of the analytes under study occurs. Micelles are dehydrated by breaking the hydrogen bonds and thus the number of water molecules in the micellar phase is reduced. At the end of the process, the sample is still spinning, which speeds up the separation of both phases, affecting the percentage of extraction efficiency [8].

The basic concept describing the process of a formation of a micelle is critical micellar concentration (CMC). In colloidal and surface chemistry, CMC is defined as the concentration above which micelles are formed. At a low concentration of surfactant, surfactant molecules are deposited on the surface. When more surfactant is added, the surface tension of the solution starts to drop sharply because more and more surfactant molecules are on the surface. As the surface becomes saturated, the addition of surfactant molecules leads to the formation of micelles. This concentration point is called the critical concentration of micelles. Three different phases can be identified: At a very low concentration of surfactant, only a small change in surface tension is detected, the addition of 
surfactant drastically reduces surface tension, and at the CMC point the surface becomes saturated, and surfactant molecules that are added do not affect the surface tension [9]. The lower critical micelle concentration is generally preferred because it ensures that the micelles will not destabilize during dilution. There are different methods for measuring CMC. These methods take advantage of the fact that the macroscopic properties of the aqueous dispersion of micellar aggregates change deeply into critical micellar concentrations. For example, the surface tension gradually decreases when molecules bind to the aqueous air interface, which continues until the surface tension reaches the limit value and the point at which the addition of further molecules to the aqueous dispersion will not result in a combination of molecules on the surface but will aggregate the molecules in the micelles. Measurements of surface tension as a function of concentration thus provide for the determination of CMC [13].

The whole process resembles traditional liquid-liquid extraction, the only difference being that the "organic" phase is produced in the aqueous phase, transforming the previously homogeneous solution into a heterogeneous one, simply by collecting previously-dispersed hydrophobic suspensions. When the solution conditions, such as temperature and pressure, are changed accordingly, phase separation occurs for the aqueous micellar solution. In other words, surfactant monomers aggregate and separate from water during the scattering of visible light. This turbid, surfactant-rich phase is loaded with the hydrophobic load of the initial solution, while the aqueous supernatant inhibits the concentration of the surfactant near CMC (critical micellar concentration) [8].

The main goal of the presented study was to compare conventional extraction (using ethanol solutions) with micellar extraction (carried out with whey protein isolated (WPI) solutions and whey protein concentrated (WPC)). The test materials consisted of dried elderberry (Sambucus nigra) fruits.

\section{Experimental Section}

\subsection{Materials and Methods}

The research materials were extracts made of elderberry. Commercial, dried elderberry fruits were used for the preparation of extracts.

For the preparation of extracts, commercial WPI and commercial WPC were used at different concentrations levels $(0.1 \%, 0.15 \%, 0.2 \%(w / v))$.

\subsection{Methods}

\subsubsection{Content of Reducing Compounds}

$0.2 \mathrm{~cm}^{3}$ of the solution was taken from the extracts obtained and diluted with $9.8 \mathrm{~cm}^{3}$ of distilled water From the solutions thus obtained $5 \mathrm{~cm}^{3}$ were removed and mixed with $0.25 \mathrm{~cm}^{3}$ of FolinCiocalteau reagent and $0.5 \mathrm{~cm}^{3}$ of a $7 \% \mathrm{Na}_{2} \mathrm{CO}_{3}$ solution was added and the mixture was stirred. Samples were incubated for $30 \mathrm{~min}$ in a dark place, and after this time the absorbance of the samples was tested. Measurement of absorbance was done with a Spectro UV-VIS Dual Beam UVS-2800 spectrophotometer, (Labomed Inc., Fort Myers, FL, USA), at wavelength $\lambda=760 \mathrm{~nm}$. The calibration curve was made from a solution of gallic acid in the concentration range of $0.01-0.11 \mathrm{mg} / \mathrm{mL}$ and the equation describing it was: $y=0.078 x+0.0552$ with $\mathrm{R}^{2}=0.9994$. The study was performed in duplicate [14].

\subsubsection{Content of Flavonoids Compounds}

Extract 1:1 with distilled water. With such dilutions prepared, $1 \mathrm{~cm}^{3}$ was withdrawn into a 10 $\mathrm{cm}^{3}$ graduated flask, then $5 \mathrm{~cm}^{3}$ of redistilled water was added and $0.3 \mathrm{~cm}^{3}$ of $5 \%(w / w)$ aqueous sodium nitrate solution was added. The resulting solution was stirred and allowed to stand for $5 \mathrm{~min}$, $0.6 \mathrm{~cm}^{3} 10 \%(w / w)$ aqueous hexahydrated aluminum chloride solution and remixed. After $5 \mathrm{~min} 2$ $\mathrm{cm}^{3}$ of a $1 \mathrm{M}$ aqueous $\mathrm{NaOH}$ solution was added and the water was redistilled to the mark. The absorbance of the samples so prepared was measured at wavelength $\lambda=510 \mathrm{~nm}$ against the zero tests. A calibration curve was made from quercetin solution in the concentration range of $0.07-0.36 \mathrm{mg} / \mathrm{mL}$ 
and the equation describing it was: $y=0.0021 x+0.1345$, at $R^{2}=0.9959$. The study was performed in duplicate [15].

\subsubsection{The Ability to Reduce Iron (III) Ions}

The study of the iron ions reduction capability was determined using the spectrophotometric method using the FRAP (Ferric Reducing Antioxidant Power) reagent [16].

Preparation of the FRAP reagent:

The acetate buffer: TPTZ: $\mathrm{FeCl}_{3} \times 6 \mathrm{H}_{2} \mathrm{O}$ was mixed in a ratio of $10: 1: 1+10 \%$ distilled water. The whole solution was incubated for $10 \mathrm{~min}$ in a shaking water bath at $37^{\circ} \mathrm{C}$.

Performing the analysis:

To $6 \mathrm{~cm}^{3}$ of the sample, $6 \mathrm{~cm}^{3}$ of the mixture was added, and a blank sample was prepared (instead of $0.2 \mathrm{~cm}^{3}$ of the sample, distilled water was added) to which the test solutions were measured. Subsequently, they were incubated $10 \mathrm{~min}$ in a water bath with a shaker at $37^{\circ} \mathrm{C}$. Absorbance was then measured at $595 \mathrm{~nm}$.

\section{Results and Discussion}

\subsection{Conventional Extraction}

The aim of the study was to compare conventional extraction with micellar extraction (using WPI and WPC) by analysis of the content of reducing compounds, flavonoids content and ability to reduce iron (III) ions on the basis of three factors: temperature, concentration, and time. The following graphs (Figures 1-12) show the effectiveness of conventional extraction.

\subsubsection{Content of Reducing Compounds}

Comparing the results of the content of reducing compounds, it can be observed that for the lowest temperature $\left(30{ }^{\circ} \mathrm{C}\right)$, the highest value was obtained in $45 \mathrm{~min}$ and the eluent was at $50 \%$, while the lowest was in $25 \mathrm{~min}$ and the eluent equal to $50 \%$. However, at the middle temperature (40 ${ }^{\circ} \mathrm{C}$ ) it can be seen that the highest value was obtained at the longest time and the lowest concentration of eluent. At the highest temperature, the highest value was determined at $45 \mathrm{~min}$ and the eluent was at $50 \%$. 
(a)

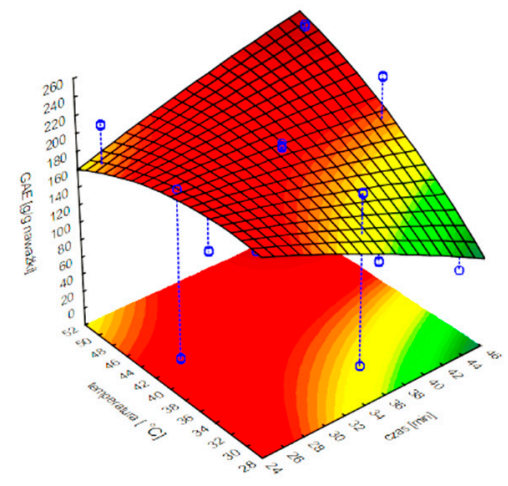

(b)

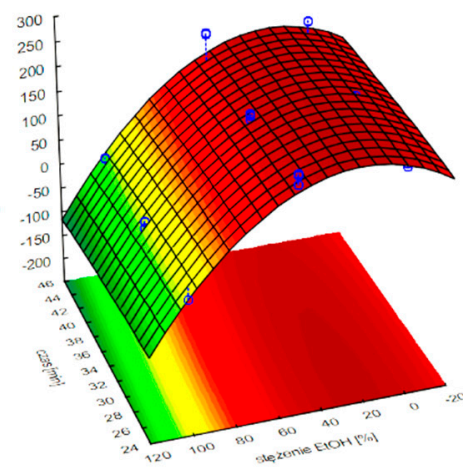

(c)

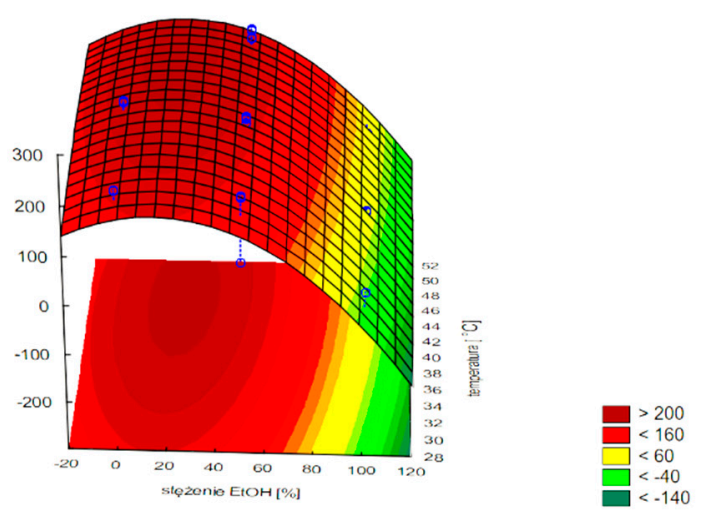

Figure 1. (a) A surface graph of the content of reducing compounds (GAE) depending on temperature and extraction time at an average concentration of 50\% EtOH. (b) A surface graph of reducing contents (GAE) depending on the time of extraction and the concentration of EtOH at an average temperature of $40^{\circ} \mathrm{C}$. (c) A surface graph of the content of reducing compounds (GAE) depending on the temperature and the concentration of $\mathrm{EtOH}$, with an average extraction time of $35 \mathrm{~min}$.

\subsubsection{The Ability to Reduce Iron (III) Ions}

The situation is different when determining the ability to reduce iron ions because, at the lowest temperature, the lowest result was obtained for $25 \mathrm{~min}$ and the eluent was $50 \%$, and the highest for $35 \mathrm{~min}$ and $100 \%$ concentration. At the highest temperature, the lowest value was tested at $45 \mathrm{~min}$ and $50 \%$ solvent, and the highest at $25 \mathrm{~min}$ and $50 \%$ solvent. 
(a)

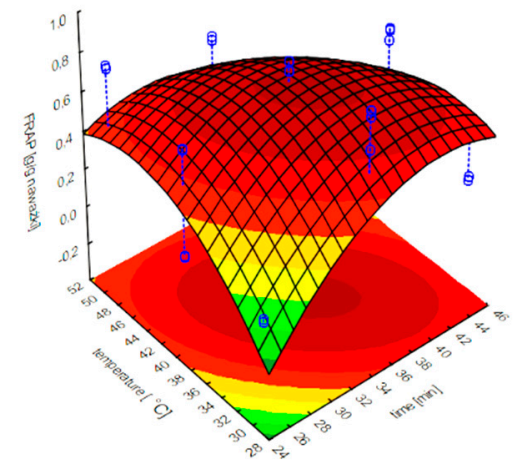

(b)

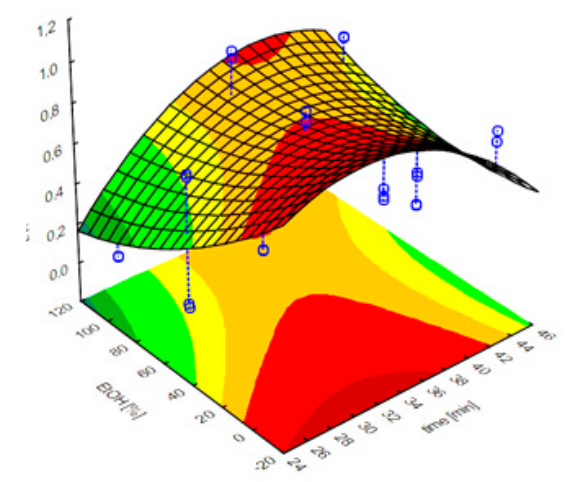

(c)

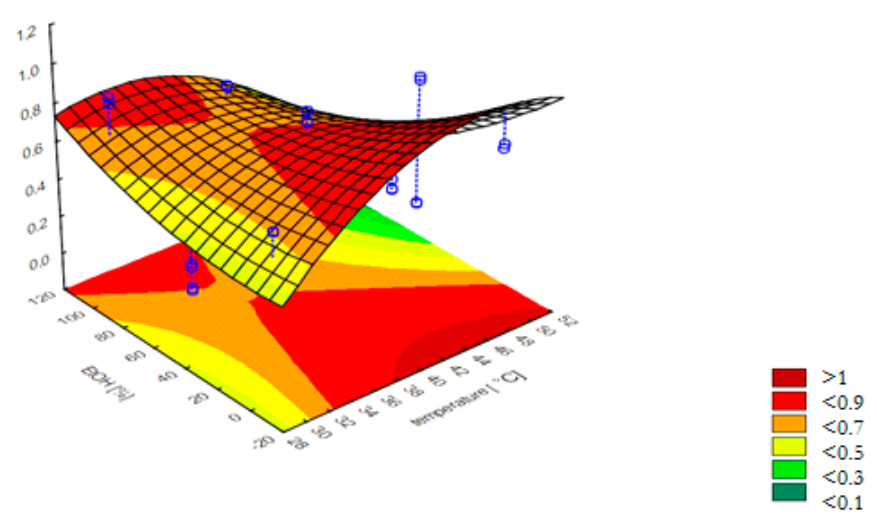

Figure 2. (a) Surface diagram of the ability to reduce iron ions depending on temperature and extraction time at an average concentration of $50 \% \mathrm{EtOH}$. (b) Surface diagram of the ability to reduce iron ions depending on the time of extraction and the concentration of $\mathrm{EtOH}$ at an average temperature of $40{ }^{\circ} \mathrm{C}$. (c) Surface diagram of the ability to reduce iron ions depending on the temperature of extraction and the concentration of $\mathrm{EtOH}$ at an average time of $35 \mathrm{~min}$.

\subsubsection{Content of Flavonoids Compounds}

The lowest content of flavonoids, at the lowest temperature, was characterized by a sample with an extraction time of $45 \mathrm{~min}$ and an eluent of $50 \%$, and the highest determined flavonoid content with an extraction time of $35 \mathrm{~min}$ and $100 \%$ concentration. At the middle temperature, the lowest value was for the time of $25 \mathrm{~min}$ and a concentration of $0 \%$, and the highest value for $35 \mathrm{~min}$ and $50 \%$ eluent. During the extraction at the highest temperature, the lowest value was obtained during $35 \mathrm{~min}$ and $0 \%$ concentration, and the highest at $35 \mathrm{~min}$ and $100 \%$ concentration. 
(a)

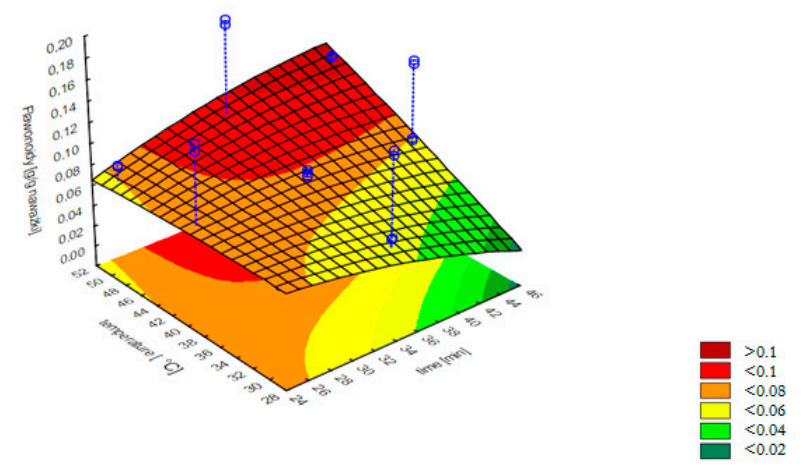

(b)

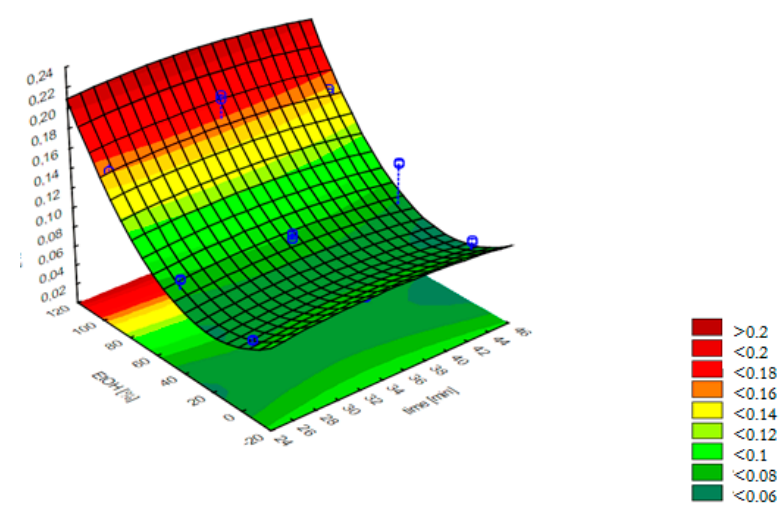

(c)

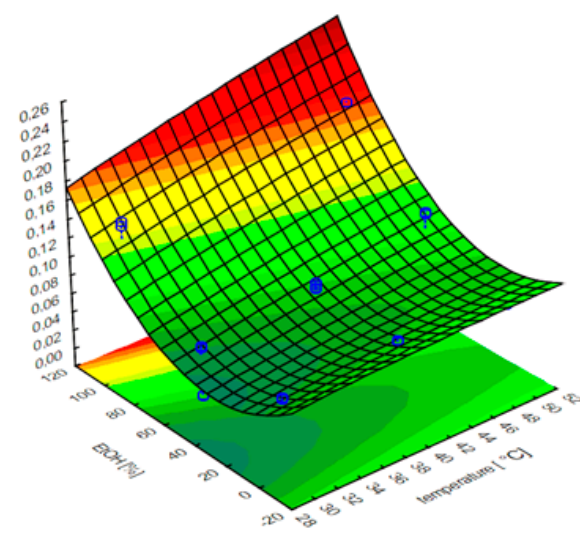

Figure 3. (a) Surface diagram of the content of flavonoids depending on the temperature and extraction time at an average concentration of $50 \% \mathrm{EtOH}$. (b) Surface diagram of the content of flavonoids compounds depending on the time of extraction and the concentration of $\mathrm{EtOH}$ at an average temperature of $40^{\circ} \mathrm{C}$. (c) Surface diagram of the content of flavonoids compounds depending on the temperature of extraction and the concentration of $\mathrm{EtOH}$ at an average time of $35 \mathrm{~min}$.

\subsection{Micellar Mediated Extraction}

\subsubsection{Content of Reducing Compounds}

When testing the content of reducing compounds with the extraction with WPC at the lowest temperature at which the extract was prepared, the highest result was demonstrated by a solution whose extraction lasted $35 \mathrm{~min}$ and $0.1 \mathrm{~g} / 100 \mathrm{~mL}$, and the lowest $45 \mathrm{~min}$ and $0.2 \mathrm{~g} / 100 \mathrm{~mL}$. At the middle temperature, the highest value was obtained at $35 \mathrm{~min}$ and $0.15 \mathrm{~g} / 100 \mathrm{~mL}$, and the lowest at $25 \mathrm{~min}$ and $0.2 \mathrm{~g} / 100 \mathrm{~mL}$ (in the micellar extraction with WPI also the lowest value was obtained at $25 \mathrm{~min}$ and $0.1 \mathrm{~g} / 100 \mathrm{~mL}$ ). At the highest temperature, the highest result was obtained at $45 \mathrm{~min}$ and $0.15 \mathrm{~g} / 100 \mathrm{~mL}$, and the lowest at $35 \mathrm{~min}$ and $0.1 \mathrm{~g} / 100 \mathrm{~mL}$. 
(a)

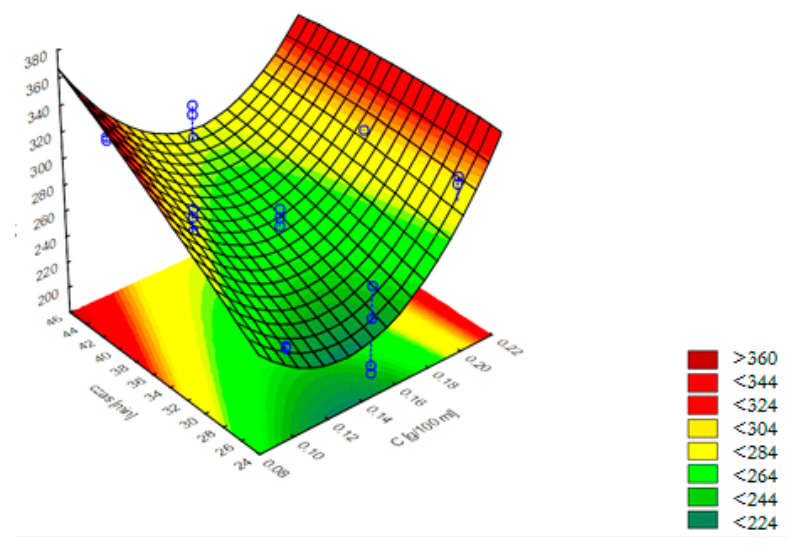

(b)
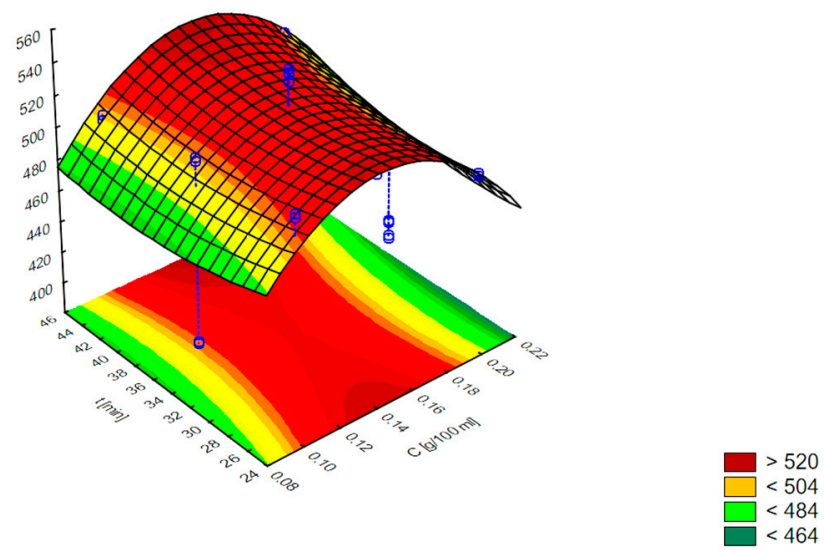

Figure 4. Surface diagram of the content of reducing compounds (GAE, Gallic Acid Equivalents) depending on time and concentration of Whey Protein Isolated (a) and Whey Protein Concentrated (b) at an average temperature $30^{\circ} \mathrm{C}$.

(a)

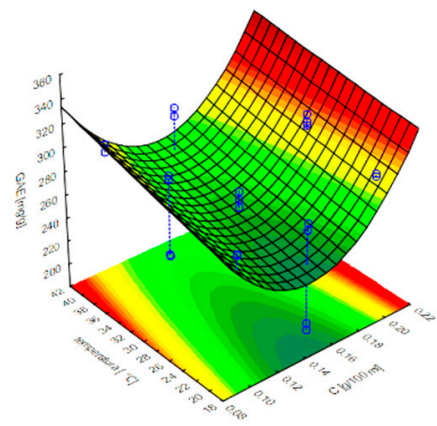

(b)

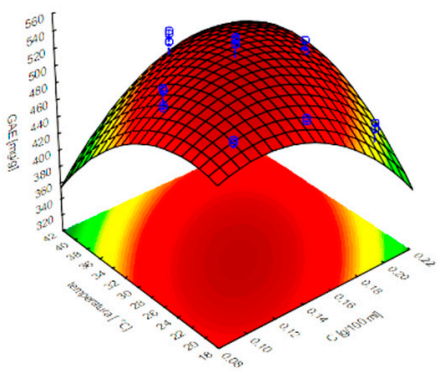

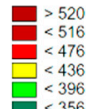

Figure 5. Surface diagram of the content of reducing compounds (GAE) depending on temperature and concentration of WPI (a) and WPC (b) at an average time $35 \mathrm{~min}$. 
(a)

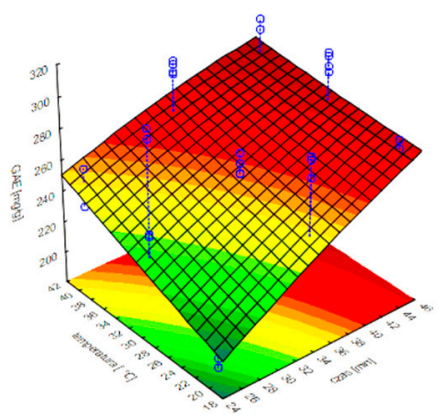

(b)

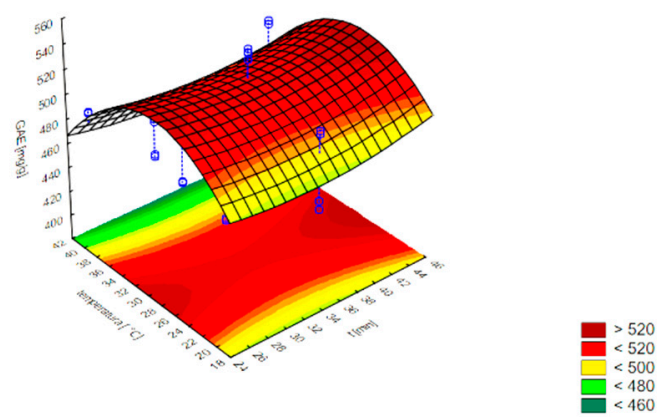

Figure 6. Surface diagram of the content of reducing compounds (GAE) depending on time and temperature of extraction at an average concertation of WPI (a) and WPC (b) 0.15 g/100 mL.

\subsubsection{The Ability to Reduce Iron (III) Ions}

In the analysis of the ability to reduce iron ions (Figures 7-9) on extracts obtained by micellar extraction at the lowest temperature, the highest yield was obtained after $45 \mathrm{~min}$ and $0.2 \mathrm{~g} / 100 \mathrm{~mL}$, and the lowest obtained after $25 \mathrm{~min}$ and $0.15 \mathrm{~g} / 100 \mathrm{~mL}$ (in micellar extraction from WPI at the same temperature the values obtained were the same). However, at the middle temperature, the highest result was obtained at $45 \mathrm{~min}$ and $0.1 \mathrm{~g} / 100 \mathrm{~mL}$, and the lowest at $25 \mathrm{~min}$ and $0.1 \mathrm{~g} / 100 \mathrm{~mL}$ (in the micellar extraction also the highest value was obtained at $45 \mathrm{~min}$ and $0.1 \mathrm{~g} / 100 \mathrm{~mL}$ ). When testing the highest temperature, it turned out that the highest value was obtained with a process lasting $25 \mathrm{~min}$ and $0.15 \mathrm{~g} / 100 \mathrm{~mL}$, and the lowest lasting $35 \mathrm{~min}$ and $0.1 \mathrm{~g} / 100 \mathrm{~mL}$ (in the micellar extraction using WPI the highest value had an extract lasting $35 \mathrm{~min}$ and $0.1 \mathrm{~g} / 100 \mathrm{~mL}$, and the lowest $25 \mathrm{~min}$ and 0.15 $\mathrm{g} / 100 \mathrm{~mL}$ ).

(a)

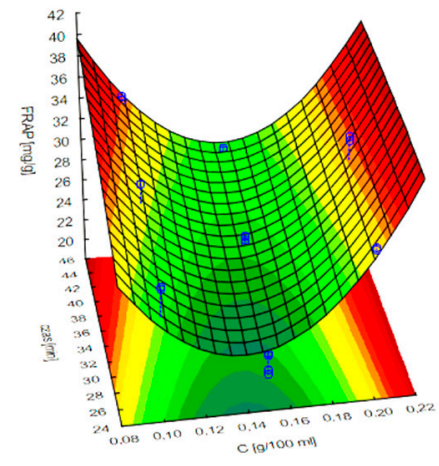

(b)

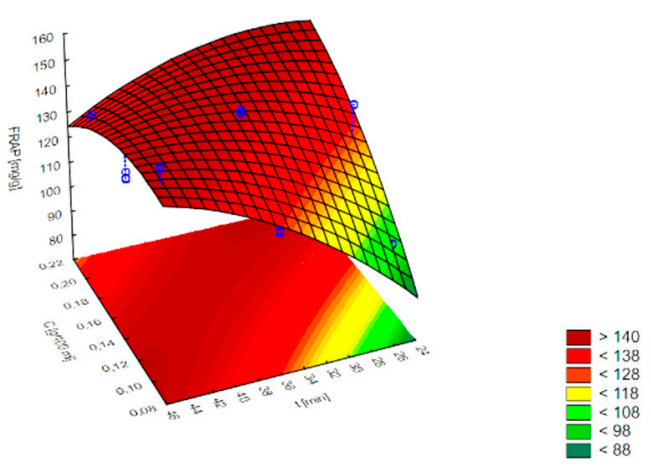

Figure 7. Surface diagram of the ability to reduce iron (III) ions depending on the concentration of WPI (a) and WPC (b) and time at an average temperature $30^{\circ} \mathrm{C}$.

(a)

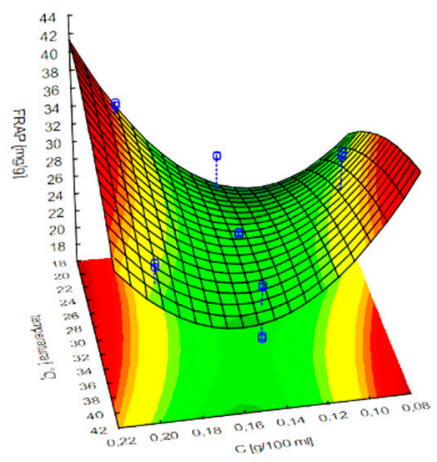

(b)

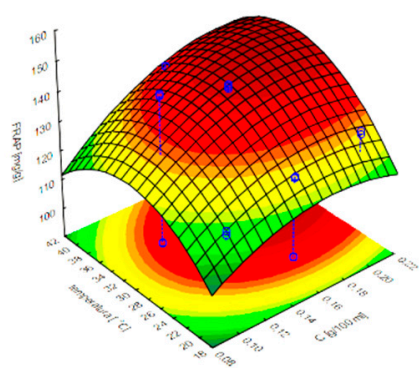

Figure 8. Surface diagram of the ability to reduce iron (III) ions depending on the concentration of WPI (a) and WPC (b) and temperature at an average time $35 \mathrm{~min}$. 
(a)

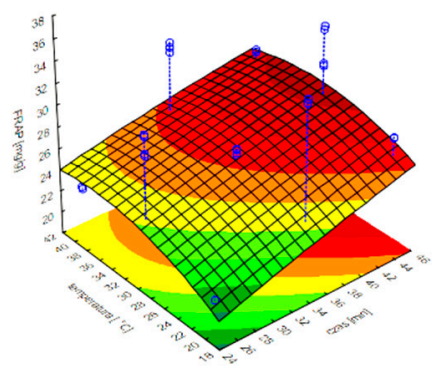

(b)

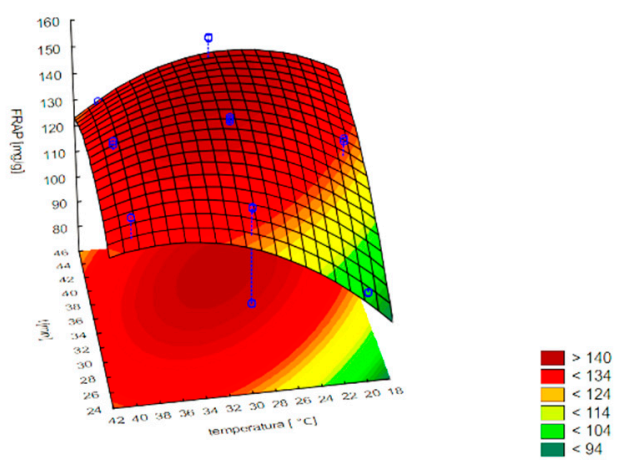

Figure 9. Surface diagram of the ability to reduce iron (III) ions depending on the time and temperature of extraction at an average concentration of WPI $0.15 \mathrm{~g} / 100 \mathrm{~mL}$.

\subsubsection{Content of Flavonoids Compounds}

In the analysis of the content of flavonoids (Figures 10-12) at the lowest temperature, the highest result had an extract of concentration $0.2 \mathrm{~g} / 100 \mathrm{~mL}$ and after $45 \mathrm{~min}$, and the lowest result was 0.1 $\mathrm{g} / 100 \mathrm{~mL}$ and time $35 \mathrm{~min}$. At the middle temperature, the highest result was obtained at $45 \mathrm{~min}$ and $0.2 \mathrm{~g} / 100 \mathrm{~mL}$, and the lowest at $35 \mathrm{~min}$ and $0.15 \mathrm{~g} / 100 \mathrm{~mL}$ (in the micellar extraction from WPI the highest result was obtained for the $0.2 \mathrm{~g} / 100 \mathrm{~mL}$ extract and time: 25 and $45 \mathrm{~min}$ ). At the highest temperature, the highest value obtained was obtained at $45 \mathrm{~min}$ and $0.15 \mathrm{~g} / 100 \mathrm{~mL}$, and the lowest at $25 \mathrm{~min}$ and $0.15 \mathrm{~g} / 100 \mathrm{~mL}$.

(a)

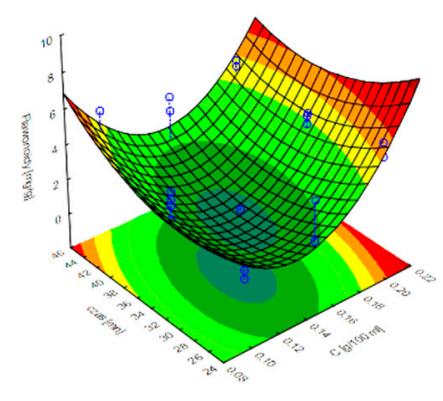

(b)

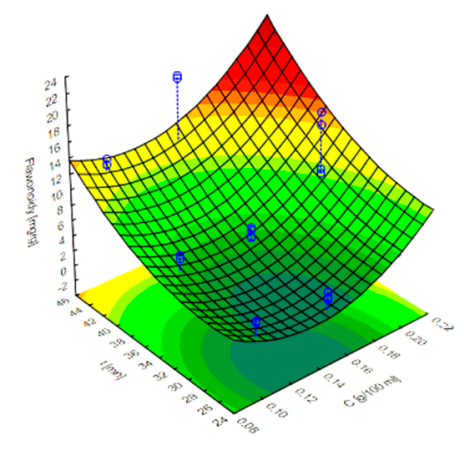

Figure 10. Surface diagram of the content of flavonoids compounds depending of the time and concentration of WPI (a) and WPC (b) at an average temperature $30^{\circ} \mathrm{C}$.

(a)

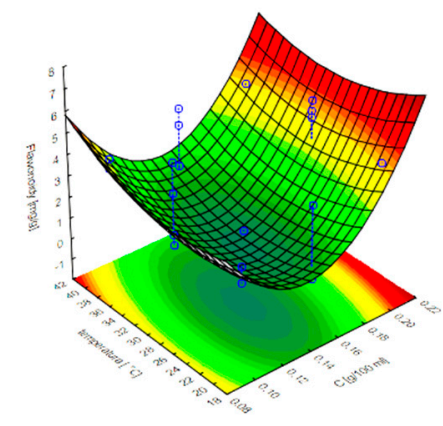

(b)

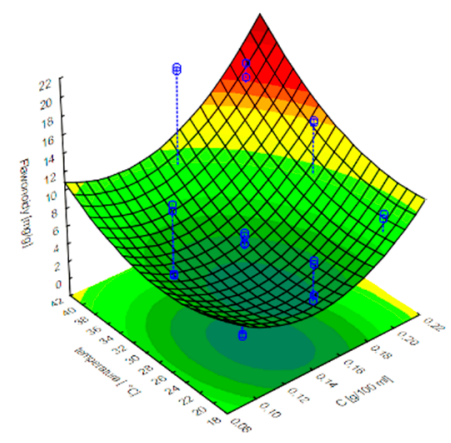

Figure 11. Surface diagram of the content of flavonoids compounds depending of the temperature and concentration of WPI (a) and WPC (b) at average time $35 \mathrm{~min}$. 
(a)

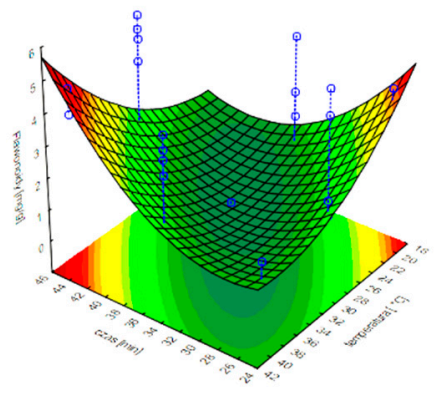

(b)

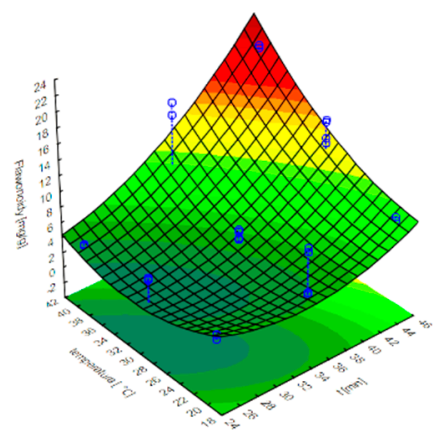

Figure 12. Surface diagram of the content of flavonoids compounds depending on the time and temperature of extraction at an average concentration of WPI (a) and WPC (b) $0.15 \mathrm{~g} / 100 \mathrm{~mL}$.

\section{Conclusions}

1. The total catechin content in the analyzed protein extracts (WPC and WPI) was higher than in the case of the ethanol extracts. In comparison to micellar extraction, more flavonoid compounds were extracted in conventional extraction. Higher reduction capacity of iron (III) ions was characterized by protein extract from WPC in contrast to extracts from WPI.

2. The concentration of the solution was of significant importance for conventional extraction efficiency.

3. Time was the factor influencing the efficiency of micellar extraction using WPC and WPI.

4. During the micellar extraction using WPC and WPI proteins, the content of flavonoid compounds increases with increasing time.

Funding: The work was financed by scientific grant No. DS3709/WTZ/2017.

\section{References}

1. Paul, B.K.; Moulik, S.P. Uses and applications of microemulsions. Curr. Sci. India 2001, 80, 990-1001.

2. Madej, K. Cloud point extraction-An alternative approach to sample preparation. Analytics 2015, 1, 50-51.

3. Szymanowski, J. Surfactant enhanced non-classical extraction. J. Radioanal. Nucl. Chem. 2000, 246, 635-642.

4. Kruglyakov, P.M. Hydrophile-Lipophile Balance of Surfactants and Solid Particles: Physicochemical Aspects and Applications; Elsevier: Amsterdam, The Netherlands; Oxford, UK, 2000; Volume 9, p. 404.

5. Quina, F.H.; Hinze, W.L. Sufractant-mediated cloud point extractions: An environmentally benign alternative separation approach. Ind. Eng. Chem. Res. 1999, 38, 4150-4168.

6. Lindman, B. Physico-chemical properties of surfactants. In Handbook of Applied Surface and Colloid Chemistry; Holmberg, K., Ed.; John Wiley \& Sons Ltd.: Chichester, UK, 2001.

7. Eastone, J. Surfactant Aggregation and Adsorption at Interfaces. In Colloid Science: Principles, Methods and Application; Cosorgove, T., Ed.; Blackwell Publishing Ltd.: Oxford, UK, 2005.

8. Paleologos, E.K.; Giokas, D.L.; Karayannis, M.I. Micelle-mediated separation and cloud-point extraction. Trends Anal. Chem. 2005, 24, 426-436.

9. Myers, D. Surfactants Science and Technology; John Wiley\& Sons: Hoboken, NJ, USA, 2012.

10. Carabias-Martinez, R.; Rodriguez-Gonzalo, E.; Moreno-Cordero, B.; Perez-Pavon, J.L.; Garcia-Pinto, C.; Laespada, E.F. Surfactant Cloud point extraction and preconcentration of organic compounds prior to chromatography and capillary electrophoresis. J. Chromatogr. A 2000, 902, 251-265.

11. Ferrera, Z.S.; Sanz, C.P.; Santana, C.M.; Rodryguez, J.S. The use of micellar systems in the extraction and pre-concentration of organic pollutants in environmental samples. Trends Anal. Chem. 2004, 23, 469-479

12. Kiszkiel, I.; Hryniewicka, M. Micellar Mediated Extraction as an alternative techniques for sample preparation for chemical analysis. Bromatol. Chem. Toksykol. 2011, XLIV, 104-116.

13. Nagadome, S.; Shibata, O.; Miyoshi, H.; Kagimoto, H.; Ikawa, Y.; Igimi, H.; Sugihara, G. Mixed systems of bile-salts-micellization and monolayer formation. ACS Symp. Ser. 1992, 501, 301-315 
14. Duda-Chodak A.; Tarko, T. Antioxidant properties of different fruit seeds and peels. Acta Sci. Pol. Technol. Aliment. 2007, 6, 29-36.

15. Cieszyńska, A.; Michocka, K.; Wieczorek, D.; Zieliński, R. Wpływ czasu ekstrakcji na aktywność przeciwrodnikową naparów herbaty zielonej. Problemy Higieny i Epidemiologii 2011, 92, 851-854.

16. Benzie J.F.F.; Strain, J.J. The Ferric Reducing Ability of Plasma (FRAP) as a measure of “Antioxidant Power": The FRAP Assay. Anal. Biochem. 1996, 239, 70-76

(C) 2019 by the authors. Licensee MDPI, Basel, Switzerland. This article is an open access article distributed under the terms and conditions of the Creative Commons Attribution (CC BY) license (http://creativecommons.org/licenses/by/4.0/). 